14 Ministero delle Finanze. Reiscrizione nella tariffa di vendita dei tabacchi lavorati adeguati alle disposizioni tecniche per il condizionamento e l'etichettatura dei prodotti del tabacco. Gazzetta Ufficiale della Repubblica Italiana 1991;247:3.

15 Breslow NE, Day NE. Statistical methods in cancer research. Vol 1. The analysis of case-control studies. Lyon: IARC, 1980.

6 La Vecchia C, Pagano R, Negri E, Decarli A. Smoking and prevalence of disease in the 1983 Italian national health survey. Int $\mathcal{f}$ Epidemiol $1988 ; 17: 50-5$
17 Wald NJ, Howard S, Evans J. Smoking tables for carbon monoxide? BMf 1976;i:434-5.

18 Wald N, Doll R, Copeland G. Trends in tar, nicotine, and carbon monoxide yields of UK cigarettes manufactured since 1934. BMJ 1981;282:763-5.

19 Fairweather FA, Carmichael IA, Phillips GF, Copeland GKE. Changes in the tar, nicotine and carbon monoxide yields of cigaretres sold in the United Kingdom. Health Trends 1981;13:77-81.

(Accepted 8 April 1993)

\title{
Prospective study of incidence of juvenile diabetes mellitus over 10 years in Dar es Salaam, Tanzania
}

\author{
Andrew B M Swai, Janet L Lutale, Donald G McLarty
}

\begin{abstract}
Objective-To ascertain the annual incidence of diabetes requiring treatment with insulin in children and adolescents aged 0-19 years in Dar es Salaam, Tanzania, during a 10 year period from 1 January 1982 to 31 December 1991.

Design-Prospective registration at a major urban hospital of all patients with newly diagnosed diabetes who were resident in Dar es Salaam.

Setting-Muhimbili Medical Centre, Dar es Salaam, Tanzania.

Patients -86 patients: 45 male, 41 female.

Results-The annual incidence of juvenile diabetes for both sexes was 1.5 per 100000 population aged $0-19$ years $(95 \%$ confidence interval $1 \cdot 3$ to $1 \cdot 7)$. Incidence per 100000 population per year increased with age: $0.6(0.0$ to 0.13$)$ in the age group 0 -4 years, $0.5(0.3$ to 0.7$)$ at $5-9$ years, $2.2(1.8$ to 2.6$)$ at $10-14$ years, and $3.4(2.9$ to 3.9$)$ at $15-19$ years.

Conclusion-Juvenile diabetes mellitus is fairly rare in sub-Saharan Africa. If environmental factors such as infection and material deprivation were important determinants of insulin dependent diabetes in Africans, as they may be in Europeans, much higher rates would have been expected unless genetic factors possibly exert a protective role. The eightfold greater incidence in African Americans than in Tanzanians may be related to greater genetic admixture in African Americans with people from countries in Europe with a high incidence.
\end{abstract}

\section{Introduction}

The incidence of juvenile diabetes varies widely throughout the world, with higher rates in white populations than in most other ethnic groups. ${ }^{2}$ Highest rates have been reported in Finland and lowest rates in China, Japan, and Korea. Incidences are also considered to decrease progressively from northern to equatorial latitudes. ${ }^{2}$ Contrary to this trend a surprisingly high prevalence of 0.95 per 1000 children aged 7-14 years was found in Khartoum, Sudan. ${ }^{3}$ Incidences, however, were not reported, and to our knowledge there are no published studies of incidence from sub-Saharan Africa. We describe the incidence and prevalence of known juvenile diabetes mellitus in

Department of Medicine, Muhimbili Medical Centre, PO Box 65001, University of Dar es Salaam, Tanzania Andrew B M Swai, associate professor

Janet L Lutale, lecturer

Donald G McLarty, professor

Correspondence to:

Dr Swai.

$B M$ 1993;306: 1570-2 $^{2}$ largest government hospital. Most African patients with diagnosed diabetes are seen in this hospital. This study includes all such patients aged 19 years and under and resident in Dar es Salaam who were registered between 1 January 1982 and 31 December $1991 .{ }^{4}$ All required insulin from the time of diagnosis.

To ensure completeness of ascertainment, doctors in the city's two major non-governmental hospitals were asked if they knew of any African patients with juvenile diabetes who were not known to us. They did not. We consider therefore that ascertainment of diagnosed juvenile diabetes was as complete as possible.

In the calculation of incidence data from the 1978 and 1988 national censuses were used. The number of children in age groups $0-4,5-9,10-14$, and $15-19$ years were noted and the difference in population numbers in each age group between 1978 and 1988 calculated. From this the annual rate of increase in the population was estimated and assumed to be the same each year. We thus derived population figures for 1982 and 1991 and used the mean of these two figures as denominator.

The estimated mean numbers of subjects in the age groups $0-4,5-9,10-14$ and $15-19$ years during the years 1982 to 1991 were $158272,142939,129719$, and 146656 , respectively (total 576586). All 95\% confidence intervals for the incidences are based on the Poisson distribution.

\section{Results}

During the 10 years of $1982-91$ inclusive 86 children and teenagers ( 45 males, 41 females) between the ages of 0 and 19 years and resident in Dar es Salaam were seen. Table I shows the number of patients seen in each age group each year. Of the 86 patients, 63 were seen in the first five years and 23 in the second five years. Only one patient below the age of 5 years was seen during the 10 years. The average crude annual incidence of diagnosed diabetes over the 10 year period for both sexes aged 0 to 19 years was 1.5 per 100000 population ( $95 \%$ confidence interval 1.3 to $1 \cdot 7$ ). Incidence per

TABLE 1-Numbers of patients with newly diagnosed juvenile diabetes seen between 1 fanuary 1982 and 31 December 1991 in Dar es Salaam, Tanzania

\begin{tabular}{lccccc}
\hline & \multicolumn{5}{c}{ Age (years) } \\
\cline { 2 - 6 } Year & $0 \cdot 4$ & $5 \cdot 9$ & $10 \cdot 14$ & $15 \cdot 19$ & $0 \cdot 19$ \\
\hline 1982 & & 1 & 3 & 7 & 11 \\
1983 & 1 & 1 & 2 & 9 & 11 \\
1984 & & & 4 & 5 & 10 \\
1985 & & 7 & 2 & 12 & 22 \\
1986 & & & 1 & 4 & 2 \\
1987 & & & 1 & 3 & 4 \\
1988 & 1 & 2 & 2 & 5 \\
1989 & & 1 & 4 & 2 & 7 \\
1990 & 1 & 7 & 28 & 50 & 86 \\
1991 & & & & &
\end{tabular}

Dar es Salaam is Tanzania's largest city with a population of 1.5 million. Most citizens are of African origin, but there are sizable minorities of Indian Asians, Arabs, and people of mixed race. In June 1981 a registry of all patients of indigenous African origin with newly diagnosed diabetes was begun in the diabetic clinic of Muhimbili Medical Centre, the city's
Dar es Salaam, Tanzania, based on registry data collected prospectively over 10 years. 


\begin{tabular}{|c|c|c|c|c|c|c|c|}
\hline \multirow[b]{2}{*}{ Country/ethnic group } & \multicolumn{4}{|c|}{ Age (years) } & \multicolumn{2}{|c|}{ Total $0-14$ years } & \multirow{2}{*}{$\begin{array}{c}\text { Total } 0-19 \text { years for } \\
\text { both sexes }\end{array}$} \\
\hline & $0 \cdot 4$ & 5.9 & $10 \cdot 14$ & $15 \cdot 19$ & Males & Females & \\
\hline Finland & $19 \cdot 1(16 \cdot 4$ to $22 \cdot 2)$ & $31.5(28.0$ to 35.4$)$ & $37.7(34 \cdot 2$ to 41.5$)$ & & $31 \cdot 1(28.4$ to 31.4$)$ & $27.9(25.3$ to 30.8$)$ & \\
\hline Britain & $9.9(9.0$ to 10.9$)$ & $13.3(12.2$ to 14.5$)$ & $17 \cdot 8(16.5$ to $19 \cdot 2)$ & & $13.8(12.9$ to 14.8$)$ & $13 \cdot 3(12.4$ to 14.3$)$ & \\
\hline France' & $2.4(1.0$ to 4.9$)$ & $4 \cdot 2(2 \cdot 4$ to $6 \cdot 9)$ & $6 \cdot 6(4 \cdot 2$ to $9 \cdot 9)$ & & $4.6(2.9$ to 6.9$)$ & $4 \cdot 3(2 \cdot 7$ to $6 \cdot 6)$ & \\
\hline Japan' & $0.4(0.3$ to 0.5$)$ & $0.7(0.6$ to 0.8$)$ & $0.7(0.6$ to 0.8$)$ & & $0.5(0.4$ to 0.6$)$ & $0.7(0.6$ to 0.8$)$ & \\
\hline \multicolumn{8}{|l|}{ USA': } \\
\hline $\begin{array}{l}\text { White Americans } \\
\text { (Rochester, Minnesota) } \\
\text { African Americans }\end{array}$ & $13.3(4.9$ to 29.0$)$ & $15 \cdot 1(6.5$ to $29 \cdot 7)$ & $33.8(19.7$ to 54.1$)$ & & $19.7(11.0$ to 32.5$)$ & $22 \cdot 1(12 \cdot 6$ to $35 \cdot 8)$ & \\
\hline (Allegheny County, Pennsylvania) & $4.3(0.6$ to 8.0$)$ & $12 \cdot 1(6 \cdot 2$ to $18 \cdot 0)$ & $20.9(13.3$ to 28.5$)$ & $11.3(6.0$ to $16 \cdot 7)$ & $11.4(6.8$ to 15.9$)$ & $13.3(8.3$ to 18.3$)$ & $12 \cdot 1(9 \cdot 2$ to 14.9$)$ \\
\hline Virgin Islands` black subjects & $3.4(0.0$ to 7.9$)$ & $5 \cdot 2(0.4$ to 10.0$)$ & $8.5(2.9$ to $14 \cdot 1)$ & $7 \cdot 1(1 \cdot 10$ to $13 \cdot 2)$ & $6 \cdot 9(3.6$ to $10 \cdot 2)$ & $4.8(1.8$ to 7.8$)$ & $6 \cdot 2(3.7$ to $8 \cdot 7)$ \\
\hline Cuba & $1 \cdot 7(1.3$ to $2 \cdot 3)$ & $3 \cdot 2(2 \cdot 6$ to 3.9$)$ & $3.0(2.5$ to 3.6$)$ & & $2.5(2 \cdot 1$ to 3.0$)$ & $2 \cdot 8(2 \cdot 4$ to $3 \cdot 3)$ & \\
\hline Tanzania & $0.06(0.0$ to 0.13$)$ & $0.5(0.3$ to 0.7$)$ & $2 \cdot 2(1.8$ to $2 \cdot 6)$ & $3.4(2.9$ to 3.9$)$ & $0.8(0.6$ to 0.9$)$ & $0.9(0.7$ to $1 \cdot 1)$ & $1.5(1.3$ to 1.7$)$ \\
\hline
\end{tabular}

${ }^{\star}$ Figures obtained from Diabetes Epidemiology Research International Study Groups.

100000 per year increased with age: $0.06(0 \cdot 0$ to $0 \cdot 13)$ in the $0-4$ years age group, $0.5(0.3$ to 0.7$)$ at $5-9$ years, $2 \cdot 2(1.8$ to $2 \cdot 6)$ at $10-14$ years, and $3 \cdot 4(2 \cdot 9$ to $3 \cdot 9)$ at $15-19$ years. For boys aged $0-14$ years the average crude annual incidence was 0.8 per $100000(0.6$ to 0.9$)$ and for girls it was 0.9 per $100000(0 \cdot 7$ to $1 \cdot 1)$.

Table II shows incidences in Dar es Salaam compared with those recorded in other countries and ethnic groups.

\section{Discussion}

Diabetes in children has always been considered rare in sub-Saharan Africa. ${ }^{5}$ The results of our study lend support to this impression. The incidence and prevalence of juvenile diabetes mellitus is similar to that in China, Japan, and the Republic of Korea, nations with the lowest recorded rates of childhood diabetes in the world. ${ }^{1}$ The incidence of diabetes in children under 5 years was particularly low, only one case being diagnosed in 10 years. Incidence increased with age in contrast to diabetes in children in Europe, in whom incidence peaks at between 10 and 14 years.

Though we are sure that all diagnosed cases of juvenile diabetes were recorded, we cannot say how many children may have died with their diabetes undiagnosed. The problem of missed diagnosis of childhood diabetes, though not unique to developing countries, ${ }^{78}$ is almost certainly much more common there. ${ }^{9}$ In spite of this problem, however, the incidence of childhood diabetes in sub-Saharan Africa is probably low.

The reason for the decrease in numbers of patients during the second five years of the study is uncertain. We carınot exclude the possibility that more patients were dying of undiagnosed disease during this period, but we think that this is unlikely because the total number of newly diagnosed patients seen annually remained around 200. In 1991 and 1992 the number of new cases registered increased to 250 and 245 respectively whereas only seven patients below 19 years were seen in each of these years. In addition, because of the existing network of doctors within Dar es Salaam newly diagnosed cases of juvenile diabetes are unlikely to have escaped our attention. Abrupt changes in the annual number of newly diagnosed cases of childhood diabetes have been noted in other countries. For example, among black children in the Virgin Islands the incidence of newly diagnosed diabetes in children of $0-14$ years rose from 6.9 per 100000 in 1983 to 23.3 per 100000 in 1984 and in 1985 fell to 3.2 per 100000 . In 1987 no new patients were seen. ${ }^{10}$

Most indigenous Tanzanians are of Bantu ethnic origin and as such share a common heritage with African Americans and West Indians, including Cubans and inhabitants of the Virgin Islands. The incidence of childhood diabetes in African Americans is about eight times that in Tanzanians; in Virgin
Islanders it is four times as great and in Cubans three times as great (table II).

To our knowledge, this is the first study from subSaharan Africa to describe incidences of diagnosed juvenile diabetes. A study from Khartoum, Sudan, has reported a surprisingly high prevalence of diabetes in $7-14$ year olds of 0.95 per $1000 .^{3}$ The annual crude incidence rate extrapolated from that study indicates a rate of 9.9 per $100000,{ }^{11}$ which is eight times as great as in Tanzania and twice as high as in France. Tanzanians are, of course, ethnically distinct from the people of northern Sudan, most of whom are of mixed Arab and black African origin. ${ }^{3}$ The Arab genetic influence may have contributed to the higher prevalence, although the rates in Khartoum are still over twice those reported among Arab children in Kuwait (4 per 100000 person years in subjects aged 0 to 19 years). ${ }^{12}$

The relative roles of genetic and environmental factors such as climate, temperature, and infection in the cause of insulin dependent diabetes and in different incidence rates are as yet uncertain. ${ }^{13}$ Both are likely to be important. The gradient in incidence observed between Tanzanians, Cubans, and African Americans could, for example, reflect in Cubans a genetic admixture of two ethnic groups with a low incidence (Bantu and Hispanic), and in African Americans a genetic admixture of an ethnic group with a low rate (Bantu) and one with a high rate (northern European). Through admixture with the white population African Americans are reported to have on average $20 \%$ of white genes. ${ }^{11}$ It has also been shown that African Americans with non-insulin dependent diabetes have more white admixture than non-diabetic African American controls. ${ }^{14}$ This admixture could result in rates much higher than in Tanzanians and Cubans but lower than in white Americans. On the other hand, the climate and environment of Tanzania and Cuba are more similar than are those of Tanzania and the United States.

Viral infections have been implicated as a possible environmental factor in insulin dependent diabetes. Evidence for this is based mainly on seasonal differences in the onset of diabetes in children. We have observed seasonality in the presentation of both insulin dependent and non-insulin dependent diabetes in Tanzania, with most cases presenting between August and November. ${ }^{15}$ No clear seasonal pattern, however, was observed in patients presenting before the age of 19 years. There was no significant difference in the incidence of diabetes between males and females, which accords with most other studies.

We did not examine in detail the socioeconomic class of the patients, but most came from socioeconomic settings that were poor in comparison to most communities in Europe. Low socioeconomic class and material deprivation are reported to be associated with insulin dependent diabetes in northern England. ${ }^{16}$ If, however, material deprivation is a universally important environmental factor in the development of 
childhood diabetes one might expect to see high rates in Africa.

We thank the director general of Muhimbili Medical Centre and the staff of the department of medicine, as well as Professor K G M M Alberti and the North East Diabetes Trust for their help and support over the years. The Diabetes Epidemiology Research International Study Group kindly provided the incidence data for Allegheny County, Pennsylvania, and the Virgin Islands.

1 Diabetes Epidemiology Research International Group. Geographic patterns of childhood insulin-dependent diabetes mellitus. Diabetes 1988;37:1113-9.

2 Rewers $\mathrm{M}$, LaPorte RE, King $\mathrm{H}$, Tuomilehto J. Trends in the prevalence and incidence of diabetes: insulin-dependent diabetes mellitus in childhood. World Health Stat $Q$ 1988;41:179-89.

3 Elamin A, Omer MIA, Hofvander Y, Tuvemo T. Prevalence of IDDM in school children in Khartoum, Sudan. Diabetes Care 1989;12:430-2.

4 Swai ABM, Lutale J, McLarty DG. Diabetes in tropical Africa: a prospective study, 1981-7. Characteristics of newly presenting patients in Dar es Salaam, Tanzania, 1981-7. BMF 1990;300:1103-6.

5 Trowell $\mathrm{HC}$, Burkitt DP, eds. Western diseases: their emergence and prevention. London: Edward Arnold, 1981:25.
6 Metcalfe MA, Baum JD. Incidence of insulin dependent diabetes in children aged under 15 years in the British Isles during 1988. BMF 1991;302:443-7. 7 Brahams D. Death of a child from undiagnosed diabetes. Lancet 1990;335 595-6.

8 Brahams D. Fatal case of undiagnosed diabetes. Lancet 1990;335:652.

9 Rwiza HT, Swai ABM, McL arty DG. Failure to diagnose diabetic ketoacidosis in Tanzania. Diabetic Med 1986;3:1811-3.

10 Tull ES, Roseman JM, Christian CLE. Epidemiology of childhood IDDM in US Virgin Islands from 1979 to 1988 . Evidence of an epidemic in early 1980 and variation by degree of racial admixture. Diabetes Care 1991:14:558-64

11 Makame MH for the DERI Study Group. Childhood diabetes, insulin, and Africa. Diabetic Med 1992;9:571-3.

12 Ekoe JM. Epidemiology and etiopathogenesis of IDDM in other ethnic groups. In: Alberti K G M M, Defronzo RA, Keen H, Zimmet P, eds. International textbook of diabetes mellitus. Chichester: Wiley, 1992:129-45.

$13 \mathrm{Papoz}$ L. Recent trends in the epidemiology of diabetes mellitus in European and Mediterranean countries. Act Diabetol Lat 1991;28:140-2.

14 Tull ES, Makame MH for the Diabetes Epidemiology Research International Group. Evaluation of Type 1 diabetes in black African-heritage population no time for further neglect. Diabetic Med 1992;9:13-21

15 McLarty DG, Yusufali A, Swai ABM. Seasonal incidence of diabetes mellitus in tropical Africa. Diabetic Med 1989;6:762-5.

16 Crow YJ, Alberti KGMM, Parkin JM. Insulin dependent diabetes in childhood and material deprivation in northern England, 1977-86. BMJ 1991;303:158-60.

(Accepted 23 March 1993)S

J Stewart Eorsyth, Simon A Ogston, Ann Clark, Charles du V Florey, Peter W Howie

Abstract

Objective-To assess the relations between early introduction of solid food and infant weight, gastrointestinal illness, and allergic illnesses during the first two years of life.

Design-Prospective observational study of infants followed up for $\mathbf{2 4}$ months after birth.

Setting-Community setting in Dundee.

Patients -671 newborn infants, of whom 455 were still available for study at 2 years of age.

Main outcome measures-Infants' diet, weight, and incidence of gastrointestinal illness, respiratory illness, napkin dermatitis, and eczema at 2 weeks and $2,3,4,6,9,12,15,18,21$, and 24 months of age.

Results-The infants given solid food at an early age (at $<8$ weeks or $8-12$ weeks) were heavier than those introduced to solids later (after 12 weeks) at 4 , 8,13 , and 26 weeks of age $(p<0 \cdot 01)$ but not at 52 and 104 weeks. At their first solid feed those given solids early were heavier than infants of similar age who had not yet received solids. The incidence of gastrointestinal illness, wheeze, and nappy dermatitis was not related to early introduction of solids. There was a significant but less than twofold increase in respiratory illness at 14-26 weeks of age and persistent cough at 14-26 and 27-39 weeks of age among the infants given solids early. The incidence of eczema was increased in the infants who received solids at 8-12 weeks of age.

Conclusion-Early introduction of solid food to infants is less harmful than was previously reported. Longer follow up is needed, but, meanwhile, a more relaxed approach to early feeding with solids should be considered.

\section{Introduction}

Successive publications of Present Day Practice of Infant Feeding have stated that infants should not be introduced to solid food before the age of 3 months and preferably not before 4 months. ${ }^{1-3}$ This view has been supported by European and American paediatric committees. ${ }^{45}$ The stated reasons for discouraging the premature introduction of solids include the possible risk of excessive weight gain, ${ }^{78}$ vulnerability of the gut to infection, ${ }^{9}$ and increased susceptibility to the development of allergic disease. ${ }^{10}$ Despite these warnings many infants receive solids before the recommended time: a survey in 1980 by the Office of Population Censuses and Surveys showed that $56 \%$ of infants were introduced to solids before 3 months of age, and the proportion had increased to $62 \%$ when the survey was repeated in $1985 .^{\circ}$ The reason for parents ignoring advice on feeding infants is unclear, but it may be that, contrary to professional belief, parents are not witnessing the predicted harmful effects of early feeding with solids and may perceive it to be beneficial to their infant.

Although earlier studies indicated that infants who received solids at an early age were significantly heavier than those who were introduced to solids at the recommended time, ${ }^{78}$ more recent reports have been unable to confirm this association. ${ }^{11-13}$ To determine the independent effect of early feeding with solids on weight, numerous other factors which may influence infant weight (such as maternal height, infant's sex, birth weight, weight on starting solids, type of milk feed, and health) must be considered. To date no studies of the effect of early feeding with solids on weight have made adjustments for relevant factors.

Although the early introduction of solids to infants in Third World countries has been shown to place them at increased risk of gastrointestinal infection, there are no data to support or refute this claim for infants in developed countries. Studies on infant feeding and allergic disease have concentrated on the effect of breast milk and artificial formulas, ${ }^{14}$ and there are few data on the effect of solid food. Recent reports from one centre in New Zealand have shown an increase in the incidence of eczema in children aged 2 and 10 years who had been introduced to solid food before 4 months of age..$^{1516}$ The incidence of asthma was not influenced by early introduction of solids," and other allergic disorders were not considered in these reports.

The aim of this study was to determine whether the early introduction of solid foods had a significant independent effect on infants' weight, gastrointestinal illness, and allergic disorders in the first two years of life after adjustment for potential confounding factors. 